\title{
United Kingdom cervical cancer screening and the costs of time and travel
}

\author{
Claire Woolley, Zoë Philips, David K. Whynes \\ University of Nottingham
}

\author{
Seonaidh C. Cotton, Nicola M. Gray \\ University of Aberdeen
}

Linda Sharp

National Cancer Registry Ireland

Julian Little

University of Ottawa

Norman R. Waugh

University of Aberdeen

\section{On behalf of the TOMBOLA Group}

Objectives: The aim of this study was to estimate the time and travel costs generated by women when attending for Papanicolaou (Pap) smear tests or colposcopy appointments in the United Kingdom, both absolutely and relative to the health service cost of the national cervical cancer screening programs.

Methods: Data were obtained from questionnaires completed by two samples of women participating in a three-center trial of management of low-grade abnormalities detected by screening ( $n=1,106$ for Pap smears and $n=1,203$ for colposcopy appointments). Women were 20 to 59 years of age and resident in Grampian or Tayside, Scotland, or Nottingham, England. Questionnaire data were supplemented with sociodemographic information previously collected at the time of recruitment to the trial.

Results: The mean total time and travel costs per attendance at a smear test and at a colposcopy appointment were estimated to be $£ 9.2$ and $£ 27.4$, respectively, averaged across the three trial areas (valued at 2002 prices). Statistically significant intercenter disparities in time and travel costs were identified, particularly with respect to colposcopy appointments. For these, time and travel costs in Nottingham were substantially less than

\footnotetext{
This study forms part of the TOMBOLA trial (ISRCTN 34841617). TOMBOLA is funded by the UK Medical Research Council and by the National Health Service in England and in Scotland. The TOMBOLA Group are as follows: Grant-holders: Current-Mark Avis, Maggie Cruickshank, Ian Duncan, Rob Hammond, David Jenkins, Jane Johnson, Julian Little (Former Principal Investigator), Graeme Murray, Keith Neal, David Parkin, Alistair Robertson, Ian Russell, Rashmi Seth, Linda Sharp, Louise Smart, Leslie Walker, Norman Waugh (Current Principal Investigator), Dave Whynes; Former-Claire Chilvers, Katherine Fielding, Eric Walker. Staff in clinical sites and co-coordinating centers: Current-Lindyanne Alexander, Hazel Brook, Rita Cannon, Claire Cochran, Brenda Cooper, Seonaidh Cotton, Marie Gallagher, Nicola Gray, Zoë Philips, Christopher Platt, Gael Reid, Claire Woolley, Rachel Yeats; Former-Marg Adrian, Ahmed AlSahab, Breda Anthony, Sarah Bell, Adrienne Bowie, Katrina Brown, Lindsey Buchanan, Claire Bushby, Keng Chew, Jeannie Dean, Ruth Dowell, Mark Dunderdale, Kate Dunn, Jane Edwards, David Evans, Julie Fenty, Dr Gabrawi, Li Guo, Maureen Heddle, Susan Henderson, Lisa Heideman, Alison Innes, Tine Iterbeke, Debbie Jobson, Steve Jones, Salli Lawson, Susanneke Lucas, Jayne MacGregor, Sheona Mackenzie, Amanda Mackie, Gillian Manderson, Ike Okorocha, Shakuntala Prabharkaran, Morag Reilly, John Rippin, Carol Robinson, Joan Rodgers, Trish Sandilands, Rose Thompson, Elizabeth Williams.
} 
those in Grampian and Tayside (£22.9, £30.2, and £32.1, respectively). Time and travel costs amount to 26 and 33 percent, approximately, over and above the direct health service costs of the English and Scottish screening programs, respectively.

Conclusions: The time and travel costs associated with participation in the UK cervical cancer screening programs are substantial and are not spatially uniform across the country.

\section{Keywords: Cervical cancer; Colposcopy; Costs; Papanicolaou test; Screening}

The cervical cancer screening programs within the United Kingdom have achieved significant reductions in both the incidence of and mortality from cervical cancer $(21 ; 26)$. Since reorganization in the late 1980 s, cervical screening has become an intensive exercise, overseen nationally but implemented locally. Computerized call/recall systems contact eligible women directly by mail every $3-5$ years and invite them to make an appointment, usually with their local general practitioners (GPs), to undergo a Papanicolaou (Pap) smear test. The Pap test identifies specific changes in the cells of the cervix, which are indicative of the possibility of future invasive disease. Tests are processed at a regional laboratory and non-negative results lead to women being either followed-up by repeat Pap testing in primary care or referred to hospital-based colposcopy clinics for confirmatory examinations. In terms of both numbers and cost, the English screening program is by far the largest in the United Kingdom. In 2002-03, around 4.2 million Pap smears were taken from 3.7 million women in England, giving rise to some 127,000 new colposcopy referrals (19). In Scotland in the same year, around 440,000 Pap tests were conducted (13).

Cervical cancer screening in the United Kingdom is provided to individual women at zero price. The annual direct costs of the programs, including those of all Pap tests, cytology, colposcopy, and program management and administration, are met by the publicly funded National Health Service (NHS). This fact notwithstanding, attendances for Pap tests and colposcopies will inevitably generate further costs, as yet unaccounted for. First, the opportunity costs of the time consumed in attending will be borne by women privately, by their employers, or by society at large. Second, women will incur travel costs when attending appointments and some might need to finance a substitute carer for their children or other dependents. Third, women may be accompanied to their appointments, resulting in additional opportunity costs and travel expenses on the part of those companions. These costs brought about by screening attendance we term "time and travel costs," and the object of the present study is to estimate time and travel costs, both absolutely and in relation to the direct NHS cost of the screening programs.

There are two reasons for estimating the time and travel costs associated with cervical cancer screening. First, such costs presently remain un-audited for the United Kingdom. Second, this costing research is an input to the economic evaluation of a multicenter randomized trial, TOMBOLA (Trial Of Management of Borderline and Other Low-grade
Abnormal smears). This trial is comparing two strategies for managing women with low-grade abnormalities detected on screening, namely, immediate hospital-based colposcopy examination versus repeat Pap smears in primary care (22). Estimates of other-than-direct costs must be included in any economic evaluation adopting a societal perspective $(12 ; 23)$. Evidence from the United States (30) has already suggested that time costs alone might be sizeable in relation to the direct health service costs of cervical screening. UK studies of screening for aortic aneurysms (3) and colorectal cancer (11) have demonstrated that time and travel costs are not spatially uniform. The geographical contrasts between the TOMBOLA trial sites enable us to establish whether the time and travel costs entailed by cervical screening also vary with the location of the screening participants.

\section{METHODS}

Data were obtained from two samples of women taking part in the TOMBOLA trial. Drawn from the general population, TOMBOLA-eligible women are between 20 and 59 years of age. Each will have recorded a low-grade abnormality (borderline or mild dyskariosis) in a Pap smear test taken routinely as part of the national programs in one of the three trial areas. Two of these areas are in Scotland: Grampian (centered on Aberdeen and Elgin) and Tayside (centered on Dundee and Perth). The third trial site is Nottingham, England. Demographically, these areas are quite different. Nottinghamshire has 71 percent of its population resident in settlements of at least 10,000 persons, with the remainder living in "accessible" small towns and villages (18). The Nottingham TOMBOLA area, centered on the city, is the most urban part of Nottinghamshire. In Tayside, a smaller proportion of the population ( 66 percent) live in urban settlements, and 4 percent live in "remote" settlements (defined as being more than 30 minutes' car drive from an urban settlement). The Grampian population is still more widespread, the corresponding proportions being 49 percent and 13 percent, respectively (28).

Data relevant to time and travel costs were obtained from questionnaires completed by women in each of the two trial arms. Data pertaining to Pap smear test attendances were collected from women randomized to receiving a further Pap test in primary care, whereas those pertaining to attending for colposcopy were collected from women randomized for examination at one of the six hospital-based clinics (two 
clinics in each of the three trial areas). Questionnaires were sent to women when their follow-up smear tests were due or with their colposcopy appointment letters, to be returned by post immediately after the appointment.

The questionnaire itself was developed from those used in the earlier UK studies mentioned above, in the light of recommendations of a working party on patient-reported costs (31). Information was obtained on the time taken in traveling to appointments, the duration of the test or investigation, the distance traveled, the mode of transport used, fares and fees paid, the nature of activities foregone by virtue of attending, and substitute caring arrangements. Equivalent data were requested for a companion, if appropriate. As with all of the questionnaires in the TOMBOLA trial, the instrument had been piloted and postal reminders were used to increase completion rates. The time and travel questionnaire data were complemented by sociodemographic information that had been collected at the time of the subjects' recruitment to the trial (also by means of a self-completed questionnaire).

The time and travel cost per attendance comprised the time and travel costs of the subject being tested or investigated, the costs of a substitute carer, and the time and travel costs of a companion, if appropriate. All costs are expressed in 2002 values. The approach to costing follows closely that adopted in an earlier time and travel cost study (11).

If the subject indicated that she and/or her companion had foregone paid employment, time was valued regardless of whether or not the opportunity costs were borne personally, by the employer, or by society as a whole, in the form of the value of lost production. The value of paid employment time was assessed at the UK average hourly rate of pay, specific to age and sex (17). Naturally, all screening subjects were females, and their companions were assumed to be likewise, unless they had been reported as being husbands or partners. Where unpaid or leisure activities were forgone on the part of subjects or companions, time was costed at $£ 3.68$ per hour, a value of nonworking time used in the evaluation of UK public transport projects (9). When subjects or companions stated they were attending during an official absence from work owing to illness, no time-based opportunity costs were deemed to have occurred.

The valuation of travel costs, exclusive of time costs, depended upon the mode of transport used. Those traveling on foot or by bicycle were assumed to incur no transport costs. Subjects using buses, railways, or taxis incurred the costs of their fares, as reported in their returned questionnaires. Companions using the bus or the train were assumed to incur the same travel cost as those incurred by subjects, although those accompanying in a taxi were presumed to have incurred no cost additional to that declared as having been paid by the subject. Total travel costs to car users (the subject with companion, if applicable) were parking fees plus $£ 0.56$ per mile traveled. This unit cost was obtained by interpolating between the Automobile Association's estimates of gross motoring costs per mile traveled for cars of engine sizes 1.1 to 1.5 liters with annual mileages of between 5,000 and 10,000 miles (1). These specific parameters were chosen because, between 1999 and 2001, 57 percent of cars driven mainly by British women had an engine size of 1.5 liters or less and the average mileage of cars driven mainly by women was 7,700 miles $(8 ; 32)$.

The cost of care for children or other dependents while the subject was attending was, in cases where care had to be purchased, the reported cost of payment. When care was unpaid, the carer's opportunity costs were valued at $£ 3.68$ per hour, as for the subject's loss of unpaid activities.

\section{RESULTS}

The overall response rate to the questionnaire was 68.1 percent. Table 1 supplies information on the socioeconomic characteristics of the entire sample, comparing the

Table 1. Sociodemographic Characteristics

\begin{tabular}{lcccc}
\hline & Responders & Nonresponders & $t$-test/ $\chi^{2}$ & $p=$ \\
\hline$n=$ & 2,269 & 1,065 & & \\
Mean age (years) & 34.9 & 30.2 & 12.4 & .00 \\
Ethnic white (\%) & 97.0 & 94.0 & 17.5 & .00 \\
Marital status (\%) & & & & \\
Married/cohabiting & 58.6 & 50.0 & 32.1 & .00 \\
$\quad$ Separated/divorced/widowed & 13.5 & 12.5 & & \\
$\quad$ Single & 27.9 & 37.5 & & \\
Employment (\%) & & & & \\
$\quad$ Full time & 49.4 & 51.6 & & \\
$\quad$ Part time & 25.3 & 19.4 & & \\
$\quad$ Student & 8.3 & 11.2 & & \\
$\quad$ Not working & 17.0 & 17.8 & & \\
Post-school training (\%) & & & & \\
$\quad$ None & 25.7 & 27.1 & & \\
$\quad$ Via employment & 19.6 & 20.3 & & \\
$\quad$ Below degree or college level & 30.0 & 27.0 & & \\
$\quad$ University/college level & 24.7 & 25.5 & & \\
\hline
\end{tabular}


Table 2. Time and Travel Characteristics of Screening Visits

\begin{tabular}{|c|c|c|c|c|}
\hline & Pap test & Colposcopy & $t$-test $/ \chi^{2}$ & $p=$ \\
\hline$n=$ & 1,066 & 1,203 & & \\
\hline Response rate $(\%)$ & 62.7 & 73.6 & 45.0 & .00 \\
\hline Mean age (years) & 35.2 & 34.7 & 1.0 & .29 \\
\hline Mean total time taken (minutes) & 52.3 & 108.0 & -32.5 & .00 \\
\hline Mean total distance traveled (miles) & 6.3 & 19.1 & -16.6 & .00 \\
\hline \multicolumn{5}{|l|}{ Mode of transport $(\%)$} \\
\hline Car & 59.9 & 75.4 & 245.4 & .00 \\
\hline Walk & 30.4 & 6.4 & & \\
\hline Bus & 7.1 & 15.1 & & \\
\hline Taxi and other & 2.6 & 3.1 & & \\
\hline For car users, parking fee charged (\%) & 6.3 & 54.7 & 391.8 & .00 \\
\hline \multicolumn{5}{|l|}{ Activities foregone $(\%)$} \\
\hline Paid employment & 47.7 & 61.3 & 56.7 & .00 \\
\hline Housework & 21.1 & 14.0 & & \\
\hline Child care & 12.5 & 9.4 & & \\
\hline Leisure & 8.6 & 5.2 & & \\
\hline Formal education & 5.3 & 6.3 & & \\
\hline Sick leave and other & 4.8 & 3.6 & & \\
\hline Subject was accompanied (\%) & 9.0 & 45.0 & 347.1 & .00 \\
\hline \multicolumn{5}{|l|}{ Identity of companion } \\
\hline Husband or partner & 58.2 & 49.9 & 3.5 & .32 \\
\hline Other relative & 33.0 & 34.7 & & \\
\hline Friend & 8.8 & 15.4 & & \\
\hline Paid employment foregone by companion (\%) & 34.4 & 52.1 & 9.6 & .00 \\
\hline Subject required a carer $(\%)$ & 20.7 & 19.4 & .1 & .74 \\
\hline
\end{tabular}

characteristics of those returning completed questionnaires (responders) with those failing so to do (nonresponders). As is evident, the size of the sample available for analysis is large absolutely, yet subject to a degree of preselection. Younger, single, nonwhite women were less likely to return a questionnaire.

Table 2 summarizes the characteristics of the two subsamples, women attending for Pap tests and those attending for colposcopies. The response rate among the latter was significantly higher, although, again, the absolute sizes of both subsamples are large. The average time taken to travel to and from and complete a Pap test was around half of the time involved in attending a colposcopy clinic, and the average distance traveled was around one third. The car was the most popular means of transport in both cases. For more than one quarter of Pap tests, women walked to their appointment, although walking was supplanted by bus travel and more extensive car use in the case of colposcopy attendances. For car users, parking charges were rarely encountered when attending for Pap tests, but were significantly more common at the colposcopy clinics. Approximately half of Pap test women were foregoing paid employment to attend, a significantly smaller proportion than among colposcopy attenders. Being accompanied while attending was more likely for colposcopy than for Pap tests, but the type of companion did not differ significantly between types of appointment. Proportionately more of the companions sacrificed paid employment in the colposcopy case. Requiring the services of a carer appeared not to be contingent upon the type of attendance.
Table 3 presents average times, distances, and estimated costs, by trial area. With respect to Pap test appointments, mean time elapsed did not differ significantly between areas (one-way analysis of variance at 5 percent). However, the mean distance traveled, the mean cost per subject, and the mean total cost per attendance were all significantly lower for Nottingham women, in comparison with their Scottish counterparts. For colposcopy appointments, the mean time elapsed, the mean distance traveled, the mean cost per subject, and the mean total cost per attendance were all significantly lower for women using the Nottingham clinics. Compared with Nottingham, the total travel times for Grampian and Tayside women were 22 and 23 percent higher, respectively. Significantly more Nottingham women were accompanied at their colposcopy visits (Chi squared $=39.5$; $p<.01)$. For the three areas combined, the mean total time and travel cost at Pap smear testing amounted to $£ 9.2$ (SD 8.7) per attendance. The equivalent amount per colposcopy attendance was $£ 27.4$ (SD 20.8). The proportion of Pap test attendances generating costs in excess of twice the full sample average was 10.2, 10.3, and 5.9 percent, for Grampian, Tayside and Nottingham, respectively. The equivalent proportions for colposcopy were $16.5,13.1$, and 3.3 percent, respectively, suggesting that the Scottish areas were responsible for a higher proportion of the higher costs in the overall distribution.

Two previous costing studies enable us to assess the significance of time and travel costs in relation to the direct costs of the cervical screening programs. First, a detailed 
Table 3. Time, Distance, and Cost, by Trial Area

\begin{tabular}{|c|c|c|c|c|c|c|}
\hline & \multicolumn{3}{|c|}{ Pap test appointment } & \multicolumn{3}{|c|}{ Colposcopy } \\
\hline & Grampian & Tayside & Nottingham & Grampian & Tayside & Nottingham \\
\hline$n=$ & 341 & 268 & 457 & 364 & 301 & 538 \\
\hline Mean age (years) & 34.3 & 35.5 & 35.7 & 33.8 & 35.2 & 35.1 \\
\hline Mean duration of appointment (minutes) & 21.0 & 23.1 & 24.1 & 48.0 & 60.5 & 42.1 \\
\hline Mean total time elapsed (minutes) & 51.8 & 54.6 & 51.2 & 112.6 & 125.7 & 94.9 \\
\hline Mean total distance traveled (miles) & 8.3 & 6.9 & 4.3 & 26.0 & 23.9 & 11.9 \\
\hline Proportion of subjects accompanied (\%) & 7.1 & 10.9 & 9.4 & 38.2 & 35.1 & 55.1 \\
\hline Proportion of subjects missing paid work $(\%)$ & 50.2 & 47.3 & 46.2 & 64.5 & 62.0 & 58.8 \\
\hline Mean cost per subject $(\mathfrak{f})$ & 9.3 & 8.9 & 6.9 & 25.3 & 26.5 & 16.3 \\
\hline Mean cost of companion ( $(\mathfrak{)})$ & 6.7 & 6.3 & 5.5 & 13.7 & 15.8 & 10.8 \\
\hline Mean cost of carer $(\mathfrak{f})$ & 3.4 & 2.8 & 2.4 & 7.0 & 8.9 & 5.6 \\
\hline Mean total cost per attendance $(\mathfrak{f})$ & 10.4 & 10.0 & 7.8 & 30.2 & 32.1 & 22.9 \\
\hline$(\mathrm{SD})$ & $(10.7)$ & $(10.7)$ & $(6.0)$ & $(23.7)$ & $(21.2)$ & $(17.2)$ \\
\hline
\end{tabular}

audit of screening resource use in Tayside estimated that the average NHS cost of providing a Pap test, including the cost of colposcopy follow-up when necessary, was approximately $£ 23$ in 1991 prices (34). Using the Hospital and Community Health Services' Pay and Price Index (5), this value translates into $£ 34$ at 2002 prices. Assuming a referral rate from Pap test to colposcopy of 3 percent (19), the expected time and travel costs entailed by a Pap test in the Tayside subsample amount to $£ 11$. Accordingly, the average gross costs of a Pap test plus follow-up in Tayside is $£ 45$, of which time and travel costs constitute 25 percent. Alternatively, time and travel costs can be expressed as a mark-up of 33 percent over direct NHS costs.

Second, the National Audit Office has estimated the annual direct NHS costs of the entire English screening program, comprising the costs of all Pap tests, cytology, colposcopy, and program management and administration, at $£ 132$ million for 1996 (4). This value translates into $£ 160$ million at 2002 prices. Were England to possess the same geographical characteristics as Nottingham, the total time and travel costs entailed by all the English Pap tests and colposcopies for 2002 would amount to $£ 36$ million, thereby representing a mark-up of 22 percent over direct NHS costs. In reality, of course, England as a whole is neither as rural as the Scottish trial areas, nor as urban as Nottingham. A more credible national estimate, therefore, results from using the three-area average costs of time and travel. On this basis, time and travel costs generated by those attending for cervical cancer screening in England would amount to approximately $£ 42$ million. The gross cost of the English program is, therefore, $£ 202$ million, of which time and travel costs comprise 21 percent. Alternatively, time and travel costs can be expressed as a mark-up over direct NHS costs of 26 percent.

As Table 1 has indicated, certain characteristics were under-represented among women responding to our questionnaire. To judge the likely impact of sample self-selection on our results, we undertook regression analyses on the Pap smear and colposcopy subsamples. The models attempted to explain total time and travel costs using age as a continuous independent variable. Being single, being ethnically white, foregoing full-time work, part-time employment, or being a student were included as dummy variables. None of the coefficients, other than that for the constant term, achieved statistical significance in either model.

As a degree of controversy currently exists over the appropriate valuation of unpaid activities $(24 ; 25)$, we undertook a simple sensitivity analysis of the results for the English program. Some have argued that unpaid time should be valued at zero, as no income is lost. Under this assumption, the estimated average total time and travel costs become $£ 8.0$ and $£ 24.2$ for the Pap test and the colposcopy attendance, respectively. English time and travel costs would thus amount to $£ 37$ million, suggesting a mark-up over direct costs of 23 percent. An alternative assumption is that unpaid time is actually more valuable than paid time, on the grounds that employers are typically obliged to pay at a disproportionate rate to encourage workers to sacrifice their leisure time. Valuing unpaid time at 150 percent of earnings produces mean costs of $£ 19.2$ and $£ 56.5$ for the Pap test and the colposcopy attendance, respectively. Under this assumption, English time and travel costs would amount to $£ 88$ million, suggesting a mark-up over direct program costs of 55 percent.

\section{DISCUSSION}

Although responses to our questionnaire displayed a degree of self-selection, the inability of the selecting variables to influence total time and travel costs significantly within the sample of responders leads us to conclude that our results are unlikely to be biased. Thus we can conclude, first, that patient-generated costs of time and travel are sizeable components of the overall costs of the cervical screening programs. Costs incurred by attending colposcopy clinics are considerably higher than those incurred when attending for Pap smear tests, and proximity is an important explanatory factor. Most Pap tests are conducted at the premises of the subject's GP, 
the initial choice of whom would have been influenced by convenience. Colposcopy clinics are typically located within hospitals, which are distributed at a far lower density than are GP premises. In addition, clinics are more likely to charge for car parking than are GPs. Women attending for colposcopy are more likely to be accompanied, most probably for two related reasons. First, referral to colposcopy after an abnormal Pap test result, and the colposcopy appointment itself, are far-from-routine events and are known to induce anxiety $(15 ; 20)$. Second, and for this very reason, NHS information leaflets supplied to attending women suggest that being accompanied might be an appropriate way of managing anxiety.

Second, time and travel costs are not spatially uniform. In the denser, urban environment of Nottingham, required travel distances are shorter, suggesting lower transport costs for two reasons: car, bus, train, and taxi costs are all broadly distance-related, and close proximity to a destination enables subjects to use a zero-price mode of transport (walking or cycling). For the relatively short distances involved in traveling to GP premises, savings on distance do not necessarily translate into savings on journey times. The translation does become more valid, however, with the longer distances required to attend colposcopy clinics. In turn, lower travel times translate directly into lower time costs on the parts of subject, companion, and carer. In entailing more travel time, attendances in the Scottish trial areas give rise to higher time costs.

The few previous studies of time and travel costs of attending any form of screening confirm our findings, that such costs are both geographically determined and sizeable in relation to direct health system costs. In the United Kingdom, a trial of screening for diabetic retinopathy estimated time and travel cost mark-ups over NHS direct costs of between 23 and 86 percent, depending on where and by whom the screening was being conducted (27). An evaluation of screening for abdominal aortic aneurysms in elderly men demonstrated that time and travel costs were significantly less when screening was conducted in a GP, rather than in a hospital, setting (3). A multicenter trial of hospital-based endoscopy as a screen for colorectal cancer examined costs for twelve areas, ranging from urban London and Leeds to rural Norfolk and Hampshire. Mean total time and travel costs per attendance by center varied between $£ 17.6$ and $£ 30.1$, as determined by the travel distances, times, and modes of transport, all of which differed between areas. The mean cost of $£ 23.3$ for the complete sample represented a mark-up of 40 percent on the direct NHS costs of the screening program, or 26 percent on the direct NHS costs of the program plus all entailed patient management $(11 ; 35)$. In Denmark, time and travel costs involved in attending routine breast cancer screening have been estimated at a 30 percent mark-up over health sector costs (2). A small study of Pap smear attendance by young women $(n=105$; mean age $=24.2$ years $)$ in the United States reported a time and travel cost mark-up of
22-32 percent over direct health sector costs, depending on assumptions made with respect to time valuation (30).

After several decades of technological stasis, cervical cancer screening in the United Kingdom is presently in a state of flux. With a view to reforming the national programs, pilot projects involving liquid-based cytology (LBC) have been operating since 2000, and the United Kingdom is evidently moving toward LBC as the technology of choice. In comparison with the conventional Pap test, LBC is expected to reduce the numbers of both false diagnoses and unsatisfactory cervical samples that necessitate re-testing. Clearly, a screening program that promises fewer unnecessary investigations and fewer initial Pap tests will suggest a reduction in time and travel costs. However, at present, the evidence for fewer attendances occurring as a result of a move from Pap testing to LBC appears equivocal $(7 ; 16)$. Therefore, no immediate assessment of LBC's impact on the time and travel costs of attendance in the United Kingdom seems possible.

This having been said, the LBC procedure facilitates testing for the presence of the human papillomavirus (HPV), a virus now known to be strongly associated with the onset of cervical cancer $(6 ; 33)$. A simulation of the management of women according to their combined LBC and HPV test results predicted a reduction in the expected number of smear tests taken by a woman throughout her lifetime, at the expense of a rise in the expected number of colposcopies (29). This prediction appears to have been confirmed by the results of the UK pilot studies (14). Given the unit costs which we have estimated, the five management scenarios examined in the pilots appear to be essentially neutral with respect to time and travel costs. With an expectation of 9.4 initial Pap tests over a lifetime, varying numbers of surveillance tests, and between .2 and .4 colposcopies depending upon scenario, undiscounted lifetime time and travel costs per woman attending vary only between $£ 98.2$ and $£ 99.5$, that is, by little more than 1 percent.

In the longer-term, however, HPV technology might be expected to exert a far more sizeable impact on both the direct and the indirect costs of screening. Trials of vaccines against HPV are well-advanced (10). Assuming our understanding of the etiology of cervical cancer is correct, widespread vaccination will reduce the incidence and transmission of HPV and thus the incidence of cervical cancer. With relatively few cases remaining to be detected, screening in its present form will become untenable. It is highly improbable that a vaccination program without a reduction in screening intensity could prove cost-effective, and a less-intensive screening protocol would reduce both NHS program costs and those time and travel costs generated as a result of women attending.

\section{POLICY IMPLICATIONS}

A new technology's cost-effectiveness ratio is often used as an indication as to whether or not it should be included in a publicly financed healthcare system's portfolio 
of interventions. Unless all rival technologies are evaluated from the same perspective, however, estimates of these ratios may be biased. For interventions dominated by hospital care, direct costs incurred by patients and families might be relatively trivial, yet this is by no means the case for clinicbased screening. Our study indicates that direct healthcare costs, over and above those met by the UK's healthcare system, are such that the incremental cost-effectiveness ratio of cervical screening from a social perspective is perhaps 2535 percent higher than that which would be estimated from a health system perspective. Failure to include such costs in an evaluation, therefore, would result in the intervention's costeffectiveness being significantly overstated. Moreover, time and travel costs incurred by service users vary with location, suggesting that equivalent variations in cost-effectiveness ratios must also exist within the system.

\section{CONTACT INFORMATION}

Claire Woolley, PhD (Claire.wooley@nottingham.ac.uk), Research Fellow, Zoë Philips, PhD (zoe.philips@ nottingham.ac.uk), Lecturer in Health Economics, David K. Whynes, MLitt (david.whynes@nottingham.ac.uk), Professor of Health Economics, School of Economics, University of Nottingham, University Park, Nottingham NG7 2RD, UK Seonaidh C. Cotton, MLitt (s.c.cotton@abdn.ac.uk), TOMBOLA Trial Manager, Department of Public Health, University of Aberdeen, Polwarth Building, Foresterhill, Aberdeen AB25 2ZD, UK

Nicola M. Gray, BA (n.gray@abdn.ac.uk), Research Fellow, Department of General Practice and Primary Care, University of Aberdeen, Foresterhill Health Centre, Westburn Road, Aberdeen AB25 2AY, UK

Linda Sharp, PhD (linda.sharp@ncri.ie), Epidemiologist, National Cancer Registry Ireland, Elm Court, Boreenmanna Road, Cork, Ireland

Julian Little, PhD (jlittle@uottawa.ca), Canada Research Chair in Human Genome Epidemiology, Department of Epidemiology and Community Medicine, University of Ottawa, 451 Smyth Road, Ottawa, Ontario, Canada K1H 8M5

Norman R. Waugh, FRCP (Edin) (n.r.waugh@abdn.ac.uk), Professor, Department of Public Health, University of Aberdeen, Polwarth Building, Foresterhill, Aberdeen AB25 2ZD, UK

\section{REFERENCES}

1. Automobile Association. Motoring costs 2002 (petrol cars). 2005. Available at: http://www.theaa.com/allaboutcars/advice/ archive.html. Accessed January 28, 2006.

2. Bech M, Gyrd-Hansen D. Cost implications of routine mammography screening of women 50-69 years in the County of Funen, Denmark. Health Policy. 2000;54:125-141.

3. Bryan S, Buxton M, McKenna M, Ashton H, Scott A. Private costs associated with abdominal aortic anuerysm screening:
The importance of private time and travel costs. J Med Screen. 1995;2:62-66.

4. Comptroller and Auditor General. The performance of the NHS cervical screening programme in England, HC 678 1997/98. London: National Audit Office; 1998.

5. Curtis L, Netten A, eds. Unit costs of health and social care 2004. Canterbury: Personal Social Services Research Unit, University of Kent; 2004.

6. Cuschieri KS, Cubie HA. The role of human papillomavirus testing in cervical screening. J Clin Virol. 2005;32S:S34S42.

7. Davey E, Barratt A, Irwig L, et al. Effect of study design and quality on unsatisfactory rates, cytology classifications, and accuracy in liquid-based versus conventional cervical cytology: A systematic review. Lancet. 2006;367:122132.

8. Department of the Environment, Transport and the Regions. National Travel Survey, 1997-1999. London: The Stationery Office; 2003.

9. Department of Transport. Values of time and operating costs, TAG unit 3.5.6. 2005. Available at: http://www.webtag.org.uk/ webdocuments/3_Expert/5_Economy_Objective/3.5.6.htm. Accessed January 27, 2006.

10. Franco EL, Harper DM. Vaccination against human papillomavirus infection: A new paradigm in cervical cancer control. Vaccine. 2005;23:2388-2394.

11. Frew E, Wolstenholme JL, Atkin W, Whynes DK. Estimating time and travel costs incurred in clinic based screening: Flexible sigmoidoscopy screening for colorectal cancer. J Med Screen. 1999;6:119-123.

12. Fryback DG, Craig BM. Measuring economic outcomes of cancer. J Natl Cancer Inst Monogr. 2004;33:134-141.

13. Information Services Division Scotland. Number of cervical smears processed at NHS laboratories in Scotland. 2005. Available at: http://www.isdscotland.org/isd/files/ cervical_cytology_TABLE_1_0106.xls. Accessed January 30, 2006.

14. Legood R, Gray A, Wolstenholme J, Moss S. Lifetime effects, costs, and cost effectiveness of testing for human papillomavirus to manage low grade cytological abnormalities: Results of the NHS pilot studies. BMJ. 2006;332:79-85

15. Maissi E, Marteau TM, Hankins M, et al. Psychological impact of human papillomavirus testing in women with borderline or mildly dyskaryotic cervical smear test results: Cross section questionnaire study. BMJ. 2004;328:1293-1296.

16. Moseley RP, Paget S. Liquid-based cytology: Is this the way forward for cervical screening? Cytopathology. 2002; 13:71-82.

17. National Statistics. Labour market: New earnings survey 2002. Newport: Office of National Statistics; 2002.

18. National Statistics. Key statistics for the urban and rural classification 2004. 2004. Available at: http://www.statistics.gov.uk/ census2001/product_ks_ur_2004.asp. Accessed January 28, 2006.

19. Office of National Statistics. Cervical screening programme, England: 2002-3. London: ONS Statistical Bulletin 2003/24; 2003.

20. Orbell S, Hagger M, Brown V, Tidy J. Appraisal theory and emotional sequelae of first visit to colposcopy following an abnormal cervical screening result. $\mathrm{Br} J$ Health Psychol. 2004;9:533-555. 
21. Peto J, Gilham C, Fletcher O, Matthews FE. The cervical cancer epidemic that screening has prevented in the UK. Lancet. 2004;364:249-256.

22. Philips Z, Gray N, Avis M, Whynes DK. Psychosocial and economic aspects of a trial of management of mild and borderline cervical abnormalities (TOMBOLA). Eur J Oncol Nurs. 2002;6:23-29.

23. Russell LB, Gold MR, Siegel JE, et al. The role of costeffectiveness analysis in health and medicine [consensus statement]. JAMA. 1996;276:1172-1177.

24. Sach TH, Whynes DK. Measuring indirect costs: Is there a problem? Appl Health Econ Health Policy. 2003;2:135-139.

25. Sach TH, Whynes DK, O’Donoghue GM, Archbold SM. Estimating time and out-of-pocket costs incurred by families attending a pediatric cochlear implant programme. Int J Pediatr Otorhinolaryngol. 2005;69:929-936.

26. Sasieni PD, Adams J. Analysis of cervical cancer mortality and incidence data from England and Wales: Evidence of a beneficial effect of screening. J R Stat Soc Ser A. 2000;163:191209.

27. Schulpher MJ, Buxton MJ, Ferguson BA, Spiegelhalter DJ, Kirby AJ. Screening for diabetic retinopathy: A relative costeffectiveness analysis of alternative modalities and strategies. Health Econ. 1992;1:39-51.

28. Scottish Executive. Urban rural classification 2003-4. 2004.
Available at: http://www.scotland.gov.uk/library5/rural/seurc00.asp. Accessed January 27, 2006.

29. Sherlaw-Johnson C, Philips Z. An evaluation of liquid-based cytology and human papillomavirus testing within the UK cervical cancer screening programme. Br J Cancer. 2004;91:84-91.

30. Shireman TI, Tsevat J, Goldie SJ. Time costs associated with cervical cancer screening. Int J Technol Assess Health Care. 2001; 17:146-152.

31. Thompson S, Wordsworth S, for the UK Working Party on Patient Costs. An annotated cost questionnaire for completion by patients. Aberdeen: Health Economics Research Unit Discussion Paper 03/01; 2001.

32. Transport 2000. Facts and figures. 2005. Available at: http://www.transport2000.org.uk/factsandfigures/Facts.asp. Accessed January 27, 2006.

33. Walboomers JMM, Jacobs MV, Manos MM, et al. Human papillomavirus is a necessary cause of invasive cervical cancer worldwide. J Pathol. 1999;189:12-19.

34. Waugh N, Smith I, Robertson A, et al. Costs and benefits of cervical screening, I: the costs of the cervical screening programme. Cytopathology. 1996;7:231-240.

35. Whynes DK, Frew EJ, Edwards R, Atkin WS. Costs of flexible sigmoidoscopy screening for colorectal cancer in the United Kingdom. Int J Technol Assess Health Care. 2003;19:384395. 